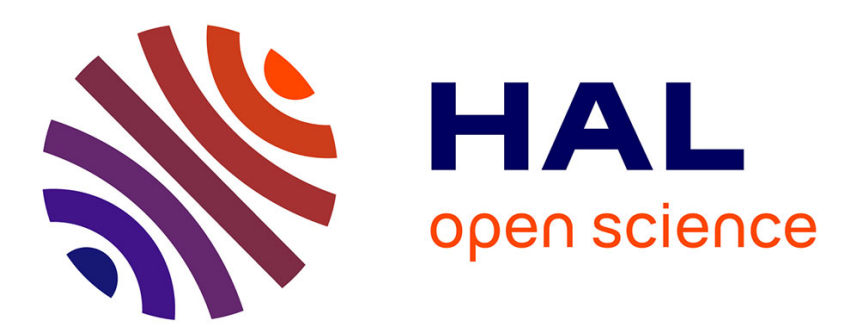

\title{
Double Dividend Hypothesis, Golden Rule and Welfare Distribution
}

Mireille Chiroleu-Assouline, Mouez Fodha

\section{To cite this version:}

Mireille Chiroleu-Assouline, Mouez Fodha. Double Dividend Hypothesis, Golden Rule and Welfare Distribution. Journal of Environmental Economics and Management, 2006, 51 (3), pp.323-335. 10.1016/j.jeem.2005.09.007 . halshs-00089895

\section{HAL Id: halshs-00089895 https://shs.hal.science/halshs-00089895}

Submitted on 24 Aug 2006

HAL is a multi-disciplinary open access archive for the deposit and dissemination of scientific research documents, whether they are published or not. The documents may come from teaching and research institutions in France or abroad, or from public or private research centers.
L'archive ouverte pluridisciplinaire HAL, est destinée au dépôt et à la diffusion de documents scientifiques de niveau recherche, publiés ou non, émanant des établissements d'enseignement et de recherche français ou étrangers, des laboratoires publics ou privés. 


\title{
Double Dividend Hypothesis, Golden Rule and Welfare Distribution $^{1}$
}

\author{
Mireille Chiroleu-Assouline ${ }^{2}$ \\ Centre d'Economie de la Sorbonne, Université Paris 1 Panthéon-Sorbonne. \\ Mouez Fodha
}

Centre d'Economie de la Sorbonne, Université Paris 1 Panthéon-Sorbonne and ERASME.

Running title: Double Dividend, Golden Rule and Welfare

\footnotetext{
${ }^{1}$ We wish to record our gratitude to the late Philippe Michel whose constructive comments contributed to improving this paper. We are also grateful to the Editor, Anastasios Xepapadeas, and two anonymous referees for helpful suggestions.

${ }^{2}$ Corresponding author. CES - Paris 1 Panthéon-Sorbonne, Maison des Sciences Economiques, 106-112 Bd de l'Hôpital, F75647 PARIS cedex 13, France, tel: 331440782 24, fax: 331440782 31, email: assoulin@univ-paris1.fr
} 


\begin{abstract}
This paper analyzes the double dividend issues within the framework of overlapping generations models. We characterize the necessary conditions for obtaining a double dividend, i.e. an improvement of environmental and non-environmental welfare when the revenue from the pollution tax is recycled into a change in the labor tax rate. We show that, depending on the initial capital stock and on the intertemporal elasticity of substitution, conditions may be defined to simultaneously allow (i) the obtaining of a long term double dividend, (ii) the economy to move closer to the modified golden rule and (iii) in the short term, an improvement in the welfare of the two present generations.
\end{abstract}

JEL classification: D60 - D62 - E62 - H23 - Q28

Key words: Environmental tax - Overlapping generations model - Golden rule - Double dividend.

Running title: Double Dividend, Golden Rule and Welfare 


\section{Introduction}

One of the advantages of the environmental tax is that it provides public revenue which can be recycled. This is the reason why it is often preferred to subsidies or emission quotas. Several authors such as Terkla [31], Parry [27], or Poterba [29] have argued that this revenue recycling could reduce or even annihilate the gross cost of the implementation of an environmental tax. As governments use the revenues from pollution taxes to decrease other distortionary taxes, environmental taxes may lead to a double dividend, according to Goulder's definition, by both improving the environmental quality and achieving a less distortionary tax system (Goulder [16]). Baumol and Oates [1], Pearce [28] and Oates [26] have suggested that these efficiency gains could be a powerful argument in favor of environmental taxation. But a great number of theoretical and empirical works refute the double dividend hypothesis (Bovenberg and de Mooij [5], [6] and [7], Bovenberg and van der Ploeg [8], [9] and [11] or Goulder [17] and Bovenberg and Goulder [3]) and, on the contrary, consider, that environmental taxes exacerbate, rather than alleviate, pre-existing tax distortions.

As well as these potential efficiency properties, environmental decisions have an impact on the welfare of both current and future generations, since environmental quality is a public good shared by different generations. These intergenerational issues on environmental externalities ${ }^{1}$ or on taxation ${ }^{2}$ have been quite widely studied in the economic literature. In an overlapping generations framework, John et al. [21] examine the effect of an environmental tax whose revenue finances a public pollution abatement activity. Fisher and van Marrewijk [15], using an endogenous growth model with pollution, derive the conditions under which a pollution tax does not slow economic growth. Bovenberg and Heijdra [4] examine the effects of a green tax on polluting capital when the tax revenue is redistributed by lump-sum intergenerational transfers and find that this tax benefits the younger generation but harms the older ones. Without studying the double dividend

\footnotetext{
${ }^{1} c f$. Howarth and Norgaard [19], Marini and Scaramozzinno [25].

${ }^{2} c f$. Kotlikoff and Summers [24], Ihori T. [20].
} 
issue, all these papers conclude that environmental taxation implies such a welfare loss for older generations that its implementation is not desirable: one of the generation which would decide it would also bear the heaviest burden. The potential contradiction between efficiency and distributional concern has been already emphasized by some works in other frameworks. While the double dividend hypothesis is rejected when the economy consists of one productive sector, using only one productive factor (labor), and one representative consumer (Bosello, Carraro and Galeotti [2]), when instead there are several productive factors and/or several consumer groups, the double dividend can be obtained but at the expense of distributive equity (Bovenberg and van der Ploeg [10], Proost and van Regemorter [30]).

Our analysis of the double dividend and welfare distribution issues takes place within a framework of overlapping generations models, which seems more convenient for analyzing such environmental problems. In the absence of altruism, the behavior of private agents is responsible for an intergenerational environmental externality. The consumption activity of present generations causes emissions of pollutants which degrade the environmental quality, harming the welfare of all future generations. The solution which is usually advocated in order to internalize this kind of externality is the implementation of environmental taxation (pigovian taxes). But such taxes imply non-environmental welfare losses for the generations bearing them.

The conditions for a double dividend have not yet been explicitly derived in a dynamic model which encompasses intergenerational externalities because balanced environmental fiscal reforms have never been considered (in John and Pecchenino [22] or John et al. [21] for example, the environmental reform increases the fiscal revenues). It is the reason why generally in these papers the generation which has to implement the reform is the one which mainly bears its costs. The main contribution of our paper is then to examine, within an appropriate demographic framework, whether a revenue-neutral increase in the pollution tax compensated for by a change in the labor tax can yield a long term double 
dividend, by (i) achieving the long term environmental objective and (ii) improving long term non-environmental welfare.

The intertemporal double dividend could be defined as an improvement of the discounted sum of non-environmental and environmental welfares of all generations. It takes into account the welfare of the generations alive during the transition between initial and final steady-states. Such a social welfare criterion leads to the modified golden rule which is preferred to the golden rule criterion because of both ethical and practical problems: the first generations would be sacrificed to the future generations while only these will fully benefit from the environmental policy; moreover, decisions about future environmental improvements are to be made by present generations which support their economic costs. The arguments given by Goulder and Stavins [18], for instance, in order to justify discounting apply here to justify the use of the modified golden rule.

Our results for the long term double dividend are then linked to the general discounting debate and contribute to the research of the conditions for an intertemporal double dividend. Even if some generations are made worse off along the transition path, any increase in the social discount factor increases the weight of the welfare of the infinite number of generations alive in the final steady-state equilibrium and (in case of a long term double dividend) increases the occurrence probability of an intertemporal double dividend. We focus then on the comparison of long term steady-state equilibria because a necessary condition to obtain an intertemporal double dividend is that the generations on the new steady-state equilibrium are made better off with respect to both environmental and non-environmental welfare. We show that, according to the discounted social welfare criterion, a double dividend can occur.

Nevertheless, the issue of acceptability by the present generations induces us to study the necessary conditions not only for environmental policy to be beneficial in the long term but also for not damaging the welfare of the generation which has to take the decision to implement the policy. 
The model is presented in the second section of this paper. It relies on standard assumptions of the overlapping generations framework (Diamond [14]). The economy consists of two periods lived individuals being affected by the quality of the environment during their whole lifetime. The government finances its spending with a labor tax and the pollution tax. In the third section, we specify the budget-neutral reform. In the fourth section, we characterize the necessary and sufficient conditions for the obtaining of long term dividends: an improvement respectively of steady-state non-environmental welfare and of environmental welfare. In section 5, we study the necessary conditions for environmental policy to be beneficial in the long term and we examine the compatibility conditions of both dividends: these necessary conditions depend on the capital intensity of the initial steady-state equilibrium relative to the optimality conditions. Section 6 shows that the fiscal change does not always harm the welfare of the present generations and that, under some peculiar assumptions about agents' preferences, it is possible to obtain both a long term double dividend and the respect of short term intergenerational equity.

\section{The model}

We assume that $N_{t}$ individuals are born in period $t$. Population grows at constant rate $n$ therefore $N_{t}=(1+n) N_{t-1}$. Each household supplies one unit of labor ${ }^{3}$ when she is young and earns a wage $w_{t}$; she divides her labor income between consumption and saving $s_{t}$. In the second period the household consumes her saving and the interest she earns. The welfare of an individual born at $t$ is measured by the intertemporal separable utility function:

$$
U\left(c_{t}^{y}, c_{t+1}^{o}, \pi_{t}, \pi_{t+1}\right)=u\left(c_{t}^{y}\right)-\gamma x\left(\pi_{t}\right)+\beta\left(v\left(c_{t+1}^{o}\right)-\gamma z\left(\pi_{t+1}\right)\right)
$$

with $c_{t}^{y}$ denoting the first-period consumption of the agent born at $t, c_{t+1}^{o}$ her secondperiod consumption and $\pi_{t+i}$ the per capita stock of pollution at $t+i$ (cf. infra). The

\footnotetext{
${ }^{3}$ Our long term view allows us to assume full employment. Moreover we focus on an efficiency double dividend (according to Goulder [16]) and not on an employment double dividend. In another paper, in a similar framework but with involuntary unemployment, we study the existence conditions for an efficiency double dividend and the role of the employment dividend (Chiroleu-Assouline and Fodha [12]).
} 
intertemporal discount factor is $\beta$ (with $0<\beta<1$ ) and $\gamma$ is the weight of the pollution externality in the welfare evaluation $(\gamma>0)$. Assume that the four instantaneous components of the utility function, $u, v,(-x)$ and $(-z)$ exhibit the usual properties: they are increasing in their argument, strictly concave and satisfy the Inada conditions.

The real interest rate is $r_{t+1}$. At period $t$, the pollution tax rate is $\tau_{t}^{e}$. The pollution is assumed to be due to consumption, with $a$ the emission rate of pollutants. The household's budget constraints can be written as follows:

$$
\left\{\begin{array}{l}
w_{t}=\left(1+a \tau_{t}^{e}\right) c_{t}^{y}+s_{t} \\
\left(1+a \tau_{t+1}^{e}\right) c_{t+1}^{o}=\left(1+r_{t+1}\right) s_{t}
\end{array}\right.
$$

The intertemporal budget constraint of the agent born at $t$ is given by:

$$
w_{t}=p_{t}^{y} c_{t}^{y}+p_{t+1}^{o} c_{t+1}^{o}
$$

where $p_{t}^{y}=\left(1+a \tau_{t}^{e}\right)$ is the first period after-tax consumption price and $p_{t+1}^{o}=\frac{1+a \tau_{t+1}^{e}}{\left(1+r_{t+1}\right)}$ the second period discounted one.

The household's problem is to choose her consumption path to maximize her lifetime utility (eq.1) subject to the intertemporal budget constraint (eq.3). The first order conditions yield:

$$
\frac{\frac{\partial U}{\partial c_{t}^{y}}}{\frac{\partial U}{\partial c_{t+1}^{o}}}=\frac{p_{t}^{y}}{p_{t+1}^{o}}
$$

This relation determines the optimal consumption and saving path of the representative household, within the Diamond framework (Diamond [14]) with a homothetic utility function $^{4}$ :

$$
\left\{\begin{array}{l}
c_{t}^{y *}=c^{y}\left(w_{t}, p_{t}^{y}, \frac{p_{t}^{y}}{p_{t+1}^{o}}\right) \\
c_{t+1}^{o *}=c^{o}\left(w_{t}, p_{t+1}^{o}, \frac{p_{t}^{y}}{p_{t+1}^{o}}\right) \\
s_{t}^{*}=s\left(w_{t}, \frac{p_{t}^{y}}{p_{t+1}^{o}}\right)
\end{array}\right.
$$

\footnotetext{
${ }^{4}$ With this assumption, saving depends on the ratio of the prices on the life cycle $\left(\frac{p_{t}^{y}}{p_{t+1}^{o}}\right)$ and linearly on the wage rate $w_{t}$. Thus, both consumptions depend also on their direct price, on $\frac{p_{t}^{y}}{p_{t+1}^{o}}$ (and then on $\left.r_{t+1}\right)$ and on $w_{t}$.
} 
The production sector consists of many firms, each of them being characterized by the same production function $f$ which has constant returns to scale and satisfies the Inada conditions. Output per capita $y_{t}$ is a function of capital per capita $k_{t}$, i.e. $y_{t}=f\left(k_{t}\right)$. The maximization problem of the representative firm is (taking the output price as numeraire):

$$
\underset{k_{t}}{\operatorname{Max}} \quad R_{t}=f\left(k_{t}\right)-w_{t}\left(1+\tau_{t}^{w}\right)-\left(r_{t}+\delta\right) k_{t}
$$

with $R_{t}$ the current net revenue, $\tau_{t}^{w}$ the labor tax rate $\left(\tau_{t}^{w}\right.$ is levied on firms and is not an income tax levied on households), $w_{t}$ the real wage rate and $\delta$ the depreciation rate of capital.

Since markets are competitive, capital and labor earn their marginal products:

$$
\left\{\begin{array}{l}
r\left(k_{t}\right)=f^{\prime}\left(k_{t}\right)-\delta \\
w\left(k_{t}, \tau_{t}^{w}\right)=\frac{f\left(k_{t}\right)-k_{t} f^{\prime}\left(k_{t}\right)}{\left(1+\tau_{t}^{w}\right)}
\end{array}\right.
$$

We assume that government spending is entirely financed by current taxes. The government's budget constraint states that its purchases ( $g_{t}$ per capita) must equal, at each period $t$, its fiscal revenues generated by the pollution tax and the labor tax. The equilibrium of the per capita government's budget is:

$$
a \tau_{t}^{e}\left(c_{t}^{y}+\frac{1}{1+n} c_{t}^{o}\right)+\tau_{t}^{w} w_{t}=g_{t}
$$

The pollution flow is assumed to be due to the households' consumption (waste production, for example), and the households' welfare is affected by the per capita stock of pollution $\pi_{t+i}$ during the first and the second-period of her life, whose dynamics is described by the following equation:

$$
\pi_{t+1}=\frac{1-h}{1+n} \pi_{t}+a\left(c_{t+1}^{y}+\frac{1}{1+n} c_{t+1}^{o}\right)
$$

where $h$ is the constant rate of natural absorption of pollution $(0<h<1)$ and $a>0$ the emission rate of pollutants. This specification encompasses both intra- and intergenerational externalities. Our model addresses special cases of rival pollution, like air pollution 
or wastes (as in Marini and Scaramazzino [25]). It could be modified to take account of global pollution: the externality would in this case depend on the total stock of pollution. But, in this last case, the model would not admit any steady-state unless the population rate of growth is nul ${ }^{5}$.

The equilibrium of the output good market can be written as follows:

$$
y_{t}=c_{t}^{y}+\frac{1}{1+n} c_{t}^{o}+(1+n) k_{t+1}-(1-\delta) k_{t}+g_{t}
$$

which yields, by substituting the zero-profit condition, the government's budget constraint (eq.7) and the household's budget constraints (eq.2) the following equation:

$$
k_{t+1}=\frac{1}{1+n} s_{t}
$$

which is similar to the equilibrium condition of the capital market, meaning that the capital stock in period $t+1$ is the amount saved by young individuals in period $t$.

Substituting the real wage and the interest rate resulting from profit maximization (eq.6) into the optimal consumptions and saving of household yields their values at the decentralized equilibrium:

$$
\left\{\begin{array}{l}
c_{t}^{y *}=c^{y}\left[w\left(k_{t}, \tau_{t}^{w}\right), p_{t}^{y}\left(\tau_{t}^{e}\right), \frac{p_{t}^{y}}{p_{t+1}^{o}}\left(\tau_{t}^{e}, \tau_{t+1}^{e}, r\left(k_{t+1}\right)\right)\right] \\
c_{t+1}^{o *}=c^{o}\left[w\left(k_{t}, \tau_{t}^{w}\right), p_{t+1}^{o}\left(\tau_{t+1}^{e}\right), \frac{p_{t}^{y}}{p_{t+1}^{o}}\left(\tau_{t}^{e}, \tau_{t+1}^{e}, r\left(k_{t+1}\right)\right)\right] \\
s_{t}^{*}=s\left[w\left(k_{t}, \tau_{t}^{w}\right), \frac{p_{t}^{y}}{p_{t+1}^{o}}\left(\tau_{t}^{e}, \tau_{t+1}^{e}, r\left(k_{t+1}\right)\right)\right]
\end{array}\right.
$$

The dynamics of the economy are obtained by using the equilibrium of the capital market (eq.10):

$$
(1+n) k_{t+1}=s\left[w\left(k_{t}, \tau_{t}^{w}\right), \frac{p_{t}^{y}}{p_{t+1}^{o}}\left(\tau_{t}^{e}, \tau_{t+1}^{e}, r\left(k_{t+1}\right)\right)\right]
$$

This equation implicitly defines $k_{t+1}$ as a function of $k_{t}$. The steady-state equilibrium is defined by $k_{t+1}=k_{t}=\hat{k}$, with $\hat{k}$ satisfying the following equation of $k$ :

$$
(1+n) k=s\left[w\left(k, \tau^{w}\right), \frac{p^{y}}{p^{o}}(r(k))\right]
$$

\footnotetext{
${ }^{5}$ Another interpretation of this model could be that of John et al. [21] who assume an externality depending on the level of the stock of environmental resources but establish the technical conditions that the utility function has to obey in order to allow the steady state of their economy to be defined as an equilibrium where all per capita variables remain constant.
} 
With the homothetic utility function, the steady-state per capita capital stock is independent ${ }^{6}$ of the pollution tax rate $\tau^{e}$ :

$$
\left\{\begin{array}{l}
\hat{c}^{y}=c^{y}\left[w\left(\hat{k}, \tau^{w}\right), r(\hat{k}), \tau^{e}\right] \\
\hat{c}^{o}=c^{o}\left[w\left(\hat{k}, \tau^{w}\right), r(\hat{k}), \tau^{e}\right] \\
\hat{s}=s\left[w\left(\hat{k}, \tau^{w}\right), r(\hat{k})\right] \\
\hat{k}=k\left(\tau^{w}\right)
\end{array}\right.
$$

At the steady-state equilibrium, the total stock of pollution is given by:

$$
\hat{\pi}=\frac{a}{n+h}\left((1+n) c^{y}\left[w\left(\hat{k}, \tau^{w}\right), r(\hat{k}), \tau^{e}\right]+c^{o}\left[w\left(\hat{k}, \tau^{w}\right), r(\hat{k}), \tau^{e}\right]\right)
$$

To ensure existence, unicity and stability of the steady-state equilibrium, we assume that, in addition to the Inada conditions and the homotheticity assumption, the two following conditions are met:

- nonvanishing labor share $\lim _{k \rightarrow 0}\left(f_{k}^{\prime} . k\right) / f(k) \in[0,1)$ (Konishi and Perera-Tallo [23]);

- $s_{r}^{\prime}(w, r)>(1+n) / f^{\prime \prime}(k)$ which means that the degree of intertemporal substitution between consumption when young and consumption when old $(\sigma)$ should not be too small, so that the substitution effect will not be dominated too much by the income effect due to changes in the rate of return ${ }^{7}$ (de la Croix and Michel [13]).

\section{The specification of the fiscal reform}

We assume an exogenous increase of the pollution tax rate, imposed by the government in order to control pollution. The amount of government purchases is assumed ex post invariant. This increase $d \tau^{e}$ of the pollution tax rate causes a variation of the labor tax rate $d \tau^{w}$. At the steady-state equilibrium, the government's budget constraint (eq.7) can be written as follows:

$$
g^{*}=\tau^{w} w\left(\hat{k}, \tau^{w}\right)+a \tau^{e}\left(c^{y}\left[w\left(\hat{k}, \tau^{w}\right), r(\hat{k}), \tau^{e}\right]+\frac{c^{o}}{1+n}\left[w\left(\hat{k}, \tau^{w}\right), r(\hat{k}), \tau^{e}\right]\right)
$$

\footnotetext{
${ }^{6}$ At the steady state, the relative price between both periods of life is simply given by $\frac{p^{y}}{p^{o}}=1+r$.

${ }^{7}$ For example, in case of a CIES utility function with intertemporal substitution elasticity $\sigma$ and a CES production function with substitution elasticity $1 /(1+\rho)$, this condition becomes: $\sigma>1 /(1+\rho)$.
} 
The link between the variations of the pollution tax and of the labor tax is obtained through the differentiation of this constraint. Any balanced fiscal reform is characterized by the following relationship between $d \tau^{e}$ and $d \tau^{w}$ :

$$
d \tau^{w}=\Lambda d \tau^{e}
$$

with $\Lambda$ the balanced fiscal reform multiplier:

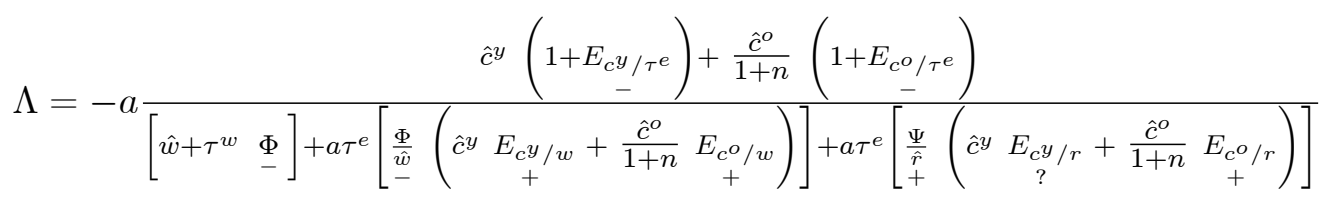

where $E_{x / y}$ denotes the elasticity of variable $x$ relative to variable $y$.

Recall that, with a homothetic utility function, the effect of the interest rate on the consumption of the young generation depends on the value of the intertemporal substitution elasticity $\left(\sigma=-\frac{U_{c^{o}}^{\prime}}{c^{o} U_{c^{o}}^{\prime \prime}}\right)$ relative to unity. More precisely, we have $\frac{\partial s}{\partial r} \lesseqgtr 0$ and then $\frac{\partial c^{y}}{\partial r} \gtreqless 0$ if and only if $\sigma \lesseqgtr 1^{8}$.

The effects of the labor tax on the wage rate and on the interest rate are respectively measured by the parameters $\Phi$ and $\Psi . \Phi=\frac{w}{\tau^{w}}\left(E_{w / \tau^{w}}+E_{w / k} E_{k / \tau^{w}}\right)$ measures both the direct and indirect effects of $\tau^{w}$ on the real wage rate: it is negative. Both effects are going the same way. As the per capita capital stock remains constant, the labor productivity, $\left(1+\tau^{w}\right) \hat{w}$, is unchanged and the wage rate may increase in order to compensate for a decrease of the labor tax $\left(E_{w / \tau^{w}}<0\right)$ : this is the direct effect. The second effect is an indirect one: a decrease of the labor tax rate enhances the per capita capital stock $\left(E_{k / \tau^{w}}<0\right)$ and increases the marginal product of labor and consequently its rate of return $\left(E_{w / k}>0\right) . \Psi=\frac{\partial r}{\partial k} \frac{\partial k}{\partial \tau^{w}}$ captures only the indirect effect of $\tau^{w}$ on the real interest rate. In case of a decrease of the labor tax, the per capita capital stock rises $\left(\frac{\partial k}{\partial \tau^{w}}<0\right)$ leading then to a decrease of the marginal product of capital and thus of its rate of return $\left(\frac{\partial r}{\partial k}<0\right)$.

\footnotetext{
${ }^{8}$ For a logarithmic utility function, $\sigma=1$, and then $\frac{\partial s}{\partial r}=\frac{\partial c^{y}}{\partial r}=0$.
} 
It might have been expected that a cut in labor tax would be in any case allowed for by an increase in the pollution tax rate, but we will now show that it is not the case here: on the one hand, the budget is assumed to be balanced ex post during each period, and on the other hand, the variation of the per capita capital stock yields opposite effects on the wage rate and on the interest rate which are the main determinants of consumption (eq.12).

Proposition 1 The sign of the balanced fiscal reform multiplier $\Lambda$ is a priori undetermined and depends on the initial tax rates and on the values of the various elasticities.

Proof. (i) The numerator measures the effect of the change in pollution tax rate on its revenue. There are both a value effect (the tax revenue increases with the tax rate, for unchanged consumption) and a fiscal base effect (consumption decreases as the tax rate increases, thus the fiscal base erodes) which work in opposite ways. As a result, this term might be positive or negative ${ }^{9}$.

(ii) $a \tau^{e} \frac{\Phi}{\hat{w}}\left(\hat{c}^{y} E_{c^{y} / w}+\frac{\hat{c}^{o}}{1+n} E_{c^{o} / w}\right)<0$ is the effect of the change of $\tau^{w}$ (via the total effects on wages) on fiscal revenues of pollution tax. There is only a fiscal base effect. (iii) $a \tau^{e} \frac{\Psi}{\hat{r}}\left(\hat{c}^{y} E_{c^{y} / r}+\frac{\hat{c}^{o}}{1+n} E_{c^{o} / r}\right) \gtrless 0$ is the effect of the change of $\tau^{w}$ (via the total effects on the interest rate) on the fiscal revenues of pollution tax levied on both generations. There is only a fiscal base effect, but the final effect stays undetermined and depends on the value of the elasticity of the consumption of the younger individuals to the interest rate. If this elasticity is positive or nil $(\sigma \leqslant 1)$, this term is unambiguously positive.

(iv) $\hat{w}+\tau^{w} \Phi \gtrless 0$ is the effect of the change of $\tau^{w}$ on its fiscal revenue. There are both a value effect (the fiscal revenue increases with the tax rate, for an unchanged wage) and a fiscal base effect (the wage decreases as the tax rate increases, thus the fiscal base erodes).

As the signs of the numerator and of the first and third terms of the denominator are undetermined, the sign of the necessary change in the labor tax is also undetermined.

\footnotetext{
${ }^{9}$ If there were two consumption goods, one clean and one dirty, the fiscal base effect would depend on the elasticity of substitution between the consumption goods. The higher this elasticity, the greater the environmental improvement, but the lower the fiscal revenue to be recycled.
} 
One could think that the case where a rise in labor tax is required could not lead to a double dividend situation but we will show later that conclusions are not so straightforward.

\section{The welfare effects of the fiscal reform}

We examine here the welfare effects of the fiscal change for a generation during its lifecycle, once the final steady-state equilibrium is reached. In this section, the welfare issue is thus a long term one (short term issues are addressed in the sixth section).

One can measure the welfare effects of small fiscal changes by the marginal excess burden. This marginal excess burden corresponds to the additional income that needs to be provided to the representative household to keep her utility at its initial level: this is the compensatory income variation, denoted $d R_{c}$. It stands for the excess welfare loss of the consumers over and above the tax revenues collected by the government and can be interpreted as the hidden costs of financing public spending: a positive value for the marginal excess burden indicates a loss in welfare after the fiscal reform.

Let us determine the compensatory income variation which, after the fiscal reform $\left(d \tau^{w}=\Lambda d \tau^{e}\right)$, would leave the level of life-cycle utility unchanged $(d U=0)$ :

$$
\frac{\partial u}{\partial c^{y}} d c^{y}-\gamma \frac{\partial x}{\partial \pi} d \pi+\beta \frac{\partial v}{\partial c^{o}} d c^{o}-\beta \gamma \frac{\partial z}{\partial \pi} d \pi=0
$$

We use the first-order conditions of the representative household's program (eq.4) and the definition of the compensatory income variation $d R_{c}$ :

$$
d w+d R_{c}=\hat{c}^{y} d p^{y}+p^{y} d c^{y}+\hat{c}^{o} d p^{o}+p^{o} d c^{o}
$$

this leads to:

$$
p^{y} d c^{y}+p^{o} d c^{o}-p^{o} \frac{\gamma}{\partial v / \partial c^{o}}\left[\frac{1}{\beta} \frac{\partial x}{\partial \pi}+\frac{\partial z}{\partial \pi}\right] d \pi=0
$$

Like Bovenberg and de Moiij [5], one can distinguish an environmental component $d R_{c}^{e}$ $\left(d R_{c}^{e}=p^{o} \frac{\gamma}{\partial v / \partial c^{o}}\left(\frac{1}{\beta} \frac{\partial x}{\partial \pi}+\frac{\partial z}{\partial \pi}\right) d \pi\right)$ and a non-environmental one $d R_{c}^{n e}\left(d R_{c}^{n e}=-d w+\right.$ 
$\left.\hat{c}^{y} d p^{y}+\hat{c}^{o} d p^{o}\right)$. The compensatory income variation is then:

$$
d R_{c}=d R_{c}^{n e}+d R_{c}^{e}
$$

According to Goulder's definition of a strong double dividend (Goulder [16]), we consider that a double dividend will be obtained if and only if environmental welfare and nonenvironmental welfare simultaneously improve. As the increase in environmental welfare becomes higher, as well as the increase in consumption prices and the wage decrease become lower, the resulting compensatory income variation will be smaller.

\subsection{The environmental dividend: the first dividend}

The variation of environmental welfare depends both on its sensitivity to per capita pollution and on the sensitivity of pollution to the consumption of the two generations ${ }^{10}$. Differentiating the expression for the steady-state per capita pollution stock (eq.13) yields:

$$
\frac{n+h}{a} d \pi=(1+n) d c^{y}\left[w\left(\hat{k}, \tau^{w}\right), r(\hat{k}), \tau^{e}\right]+d c^{o}\left[w\left(\hat{k}, \tau^{w}\right), r(\hat{k}), \tau^{e}\right]
$$

where the consumption variations are given by the following expressions:

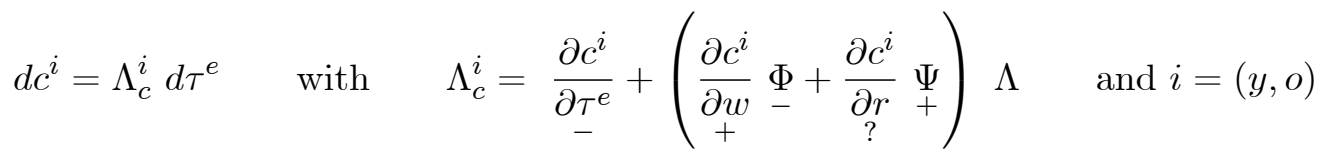

When $\sigma \leqslant 1$, the fiscal policy has the same effects on the consumption of the old and of the young generations $\left(\frac{\partial c^{i}}{\partial r} \geqslant 0\right)$. If the increase in $\tau^{e}$ requires an increase in $\tau^{w}$, both effects of wage decreasing and of consumption cost increasing diminish the consumption $\hat{c}^{i}$. But the fall in capital stock $\hat{k}$ increases the interest rate and stimulates consumption: the final effect is unknown. On the contrary, in case of a cut in labor tax $(\Lambda<0)$, consumption will decrease only if the negative effect of the pollution tax and of interest rate is greater than the positive effect allowed for by the wage augmentation $(\Phi<0)$. But, when $\sigma>1$, if the increase of pollution tax rate results in an increase in labor tax rate $(\Lambda>0)$ the effect concerning the consumption of the younger individuals is unambiguously negative (while

\footnotetext{
${ }^{10} \mathrm{An}$ environmental dividend is characterized by a negative $d R_{c}^{e}$ which occurs if and only if per capita pollution stock decreases.
} 
the effect on the consumption of the older remains ambiguous), because of the decrease in the wage rate and the rise in the first period consumption price on the one hand, and on the other hand, the rise of the interest rate which makes saving more attractive.

Finally, the variation of the per capita stock of pollution is obtained by:

$$
\frac{n+h}{a} d \pi=\left((1+n) \Lambda_{c}^{y}+\Lambda_{c}^{o}\right) d \tau^{e}
$$

Let us see the precise links between $\Lambda, \Lambda_{c}^{y}$ and $\Lambda_{c}^{o}$ :

$$
\Lambda_{c}^{i}<0 \text { if and only if }\left(\frac{\partial c^{i}}{\partial w} \Phi+\frac{\partial c^{i}}{\partial r} \Psi\right) \Lambda<-\frac{\partial c^{i}}{\partial \tau^{e}} \quad \text { with } i=(y, o)
$$

At each period of the household's life, when the rise in the pollution tax rate can be balanced through a reduction of the tax rate on labor, the final effect on consumption will be negative if and only if the income effect is lower than the price effect, that is if the consumption rise (due to the wage increase and eventually to the interest rate decrease) is more than compensated for by the decrease due to price augmentation ; the first dividend

will be all the more easy to obtain as $\frac{\partial c^{y}}{\partial r} \geqslant 0$ i.e. as $\sigma \leqslant 1$. But when $\Lambda>0$, the lower are the income effects as compared to the price effects and the more easily will the first dividend be obtained. In this case, $\sigma>1$ (i.e. $\Lambda_{c}^{y}<0$ ) increases the probability of obtaining the first dividend.

\subsection{The existence conditions of a second dividend}

In this framework, the second dividend is obtained when the non-environmental compensatory income variation is negative $\left(d R_{c}^{n e}<0\right)$. The final result will depend on the effect of the fiscal reform on the wage rate and on prices, but not on the allocation choice between present and future consumption. Consequently, the intertemporal elasticity of substitution, $\sigma$, which played the crucial role for the obtaining of the first dividend, is pointless here.

- Welfare effect through the wage:

$$
d w=\Phi d \tau^{w}=\Phi \Lambda d \tau^{e}
$$


As $\Phi<0$, the effect on the wage depends only on the sign of $\Lambda$. If the pollution tax rise is balanced by a decrease of the tax rate on labor, the wage will increase, playing in favor of the double dividend hypothesis (the marginal excess burden would be lower).

- Welfare effects through price variations:

$$
\left\{\begin{array} { r l } 
{ d p ^ { y } } & { = \frac { \partial p ^ { y } } { \partial \tau ^ { e } } d \tau ^ { e } } \\
{ d p ^ { o } } & { = ( \frac { \partial p ^ { o } } { \partial \tau ^ { e } } + \frac { \partial p ^ { o } } { \partial r } \Psi \Lambda ) d \tau ^ { e } }
\end{array} \Leftrightarrow \left\{\begin{array}{l}
d p^{y}=a d \tau^{e} \\
d p^{o}=\frac{1}{1+r}\left(a-p^{o} \Psi \Lambda\right) d \tau^{e}
\end{array}\right.\right.
$$

The first-period consumption price increases unambiguously but the second-period price may diminish if $\Lambda>0$ (the second-period price decreases when the interest rate $r$ rises). In the case of a decrease of the tax rate on labor $(\Lambda<0)$, both prices increase, which leads to a rise in the marginal excess burden of the fiscal reform.

The final effect on non-environmental welfare is measured by the compensatory income variation $d R_{c}^{n e}$ :

$$
\begin{aligned}
d R_{c}^{n e} & =-d w+\hat{c}^{y} d p^{y}+\hat{c}^{o} d p^{o} \\
& =\left[-\Phi \Lambda+\hat{c}^{y} a+\frac{1}{1+r} \hat{c}^{o}\left(a-p^{o} \Psi \Lambda\right)\right] d \tau^{e}
\end{aligned}
$$

Even in the more intuitive case of a decrease in the labor tax $(\Lambda<0)$ and of a reduction of consumption during both periods $\left(\Lambda_{c}^{y}<0\right.$ and $\Lambda_{c}^{o}<0$ or at least of global consumption $\left.(1+n) \Lambda_{c}^{y}+\Lambda_{c}^{o}<0\right)$ which leads to an environmental dividend, the existence of the double dividend depends on the relative magnitude of the effects on the wage, on the environmental welfare, on the fiscal base of the pollution tax and on the intertemporal elasticity of substitution.

\section{Double Dividends and the Golden Rule}

In this section, we analyze the compatibility conditions between both long term dividends. We show that, whatever the sign of the variation in the labor tax rate $\tau^{w}$ implied by the 
environmental fiscal reform, the obtaining of a double dividend depends on the capital intensity of the initial steady-state and on the intertemporal elasticity of substitution $\sigma$.

Rewriting $d R_{c}^{n e}$ (eq.17) while differentiating the equilibrium household's budget constraint (eq.3), leads to the following new definition of the non-environmental compensatory income variation:

$$
d R_{c}^{n e}=-p^{y} d c^{y}-p^{o} d c^{o}
$$

It is worth noting here that the second dividend cannot occur if consumption falls during both periods; symmetrically, the first dividend will be excluded if consumption rise during both periods. Finally, the only case of double dividend is the one where both consumptions go in opposite ways. We will limit the study to this case.

Notice that, ceteris paribus, the crucial parameter for the obtaining of the double dividend is the elasticity of consumption to the interest rate. This is indeed the only effect which can play in opposite ways on the consumption of the older and of the younger generation, under homothetic preferences. This property clearly appears by using eq.(15), rewritten in terms of elasticities:

$$
\frac{\Lambda_{c}^{y}}{\hat{c}^{y}}-\frac{\Lambda_{c}^{o}}{\hat{c}^{o}}=\left(E_{c^{y} / r}-E_{c^{o} / r}\right) \underbrace{\frac{E_{r / k} E_{k / \tau^{w}}}{\tau^{w}}}_{+} \Lambda
$$

Combining eq.(16) and eq.(18) leads to the following necessary condition for both dividends to be obtained together:

$$
0>\Lambda_{c}^{y}+\frac{1}{1+n} \Lambda_{c}^{o}>\frac{r-n}{(1+r)(1+n)} \Lambda_{c}^{o}
$$

This condition induces us to refer to the per capita capital stock defined by the golden rule $^{11}$ and to take into account the inefficiency property of the overlapping generations models, in a competitive framework ${ }^{12}$, which requires us to distinguish two cases: underaccumulation and over-accumulation of capital. Nevertheless the social optimum for this

\footnotetext{
${ }^{11}$ The golden rule determines the per capita capital stock $\hat{k}_{g}$ which maximizes the steady-state consumption. It is given by the equality between the net capital return $f^{\prime}\left(\hat{k}_{g}\right)-\delta$ and the growth rate of population $n$.

${ }^{12}$ The competitive equilibrium of an OLG model is in general not efficient: it is characterized either by over-accumulation $\hat{k}>\hat{k}_{g}$ (or equivalently $\hat{r}<n$ ) or under-accumulation $\hat{k}<\hat{k}_{g}$.
} 
economy is defined by the modified golden rule (as we consider that the social planner uses a discounted welfare criterion), which yields the optimal level of capital $\hat{k}_{\theta}$, with $\theta<1$ the social discount factor ${ }^{13}$.

Proposition 2 When the initial competitive steady-state equilibrium is characterized by under-accumulation (resp. over-accumulation), the necessary conditions for a double dividend are the following:

$$
\begin{array}{l|l}
\Lambda_{c}^{y}>0 \\
\Lambda_{c}^{o}<0
\end{array} \quad\left(\begin{array}{l|l}
\text { resp. } & \Lambda_{c}^{y}<0 \\
\Lambda_{c}^{o}>0
\end{array}\right)
$$

Proof. See equation (20)

By writing the equilibrium of the output good market (eq.9) at the steady-state equilibrium, let us define the link between the net output (sum of aggregate consumption and exogenous public expenditures $g^{*}$ ) and the per capita capital stock $k$ :

$$
C(k)=c^{y}(w(k), r(k))+\frac{c^{o}(w(k), r(k))}{1+n}+g^{*}=f(k)-(n+\delta) k
$$

This function is strictly concave and verifies: $C(0)=0, C^{\prime \prime}(\cdot) \leqslant 0, \lim _{k \rightarrow 0} C^{\prime}(\cdot)=+\infty, \lim _{k \rightarrow \infty} C^{\prime}(\cdot)=$ $-\infty, C^{\prime}(\cdot) \geqslant 0$ if $\left.\left.k \in\right] 0 ; \hat{k}_{g}\right]$ and $C^{\prime}(\cdot)<0$ elsewhere $^{14}$.

This writing allows us to easily deduce how the first dividend can be obtained because the pollution stock decreases if and only if net output decreases: in case of underaccumulation, the balanced environmental fiscal reform ( $g$ exogenous) has to decrease the per capita capital stock $\hat{k}$ while it has to increase it in case of over-accumulation (see Figure 1).

Proposition 3 When the initial steady-state competitive equilibrium is characterized by $\hat{k}_{\theta}<\hat{k}<\hat{k}_{g}$, the necessary conditions for obtaining a double dividend are (i) $\Lambda>0$ and (ii) $\sigma<1$; in this case, the environmental reform moves the economy closer to the modified golden rule.

\footnotetext{
${ }^{13}$ The optimal level of capital $\hat{k}_{\theta}$ is lower than $\hat{k}_{g}$ because $\theta\left(f^{\prime}\left(\hat{k}_{\theta}\right)+(1-\delta)\right)=f^{\prime}\left(\hat{k}_{g}\right)+(1-\delta)$. There is necessarily under-accumulation at $\hat{k}_{\theta}$.

${ }^{14}$ The golden rule capital stock $\hat{k}_{g}$ also maximizes net output in our case.
} 


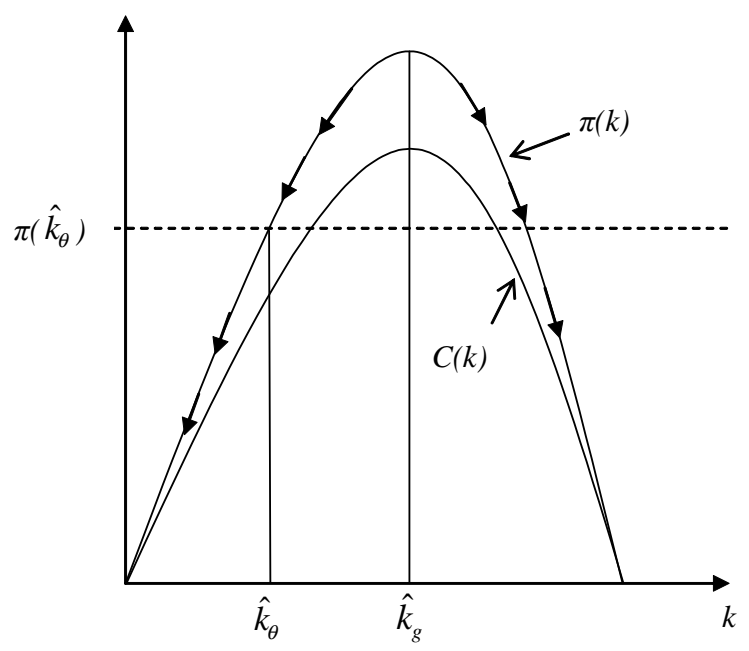

Figure 1: Long term net output, pollution and first dividend

Proof. (i) If $\hat{k}_{\theta}<\hat{k}<\hat{k}_{g}$, the first dividend needs to reduce $\hat{k}$ ( since $C^{\prime}(\cdot) \geqslant 0$ ). As $E_{k / \tau^{w}}<0$, this can only be obtained through an increase of $\tau^{w}: \Lambda$ needs to be positive, which means that one of the taxes has to be Laffer-inefficient. Because $k$ decreases, the economy is moving closer to the social optimum even though it is moving away from the golden rule.

(ii) The rise in $\tau^{w}$ induces a loss of wage which negatively affects both consumptions, but it increases the interest rate and then the crucial parameter is the relative sensitivity of consumptions to the interest rate. As proposition 2 stated, the double dividend can only be achieved, in this case of under-accumulation, if $\Lambda_{c}^{y}>0$ and $\Lambda_{c}^{o}<0$. We have previously shown (eq.(19)), that, for $\Lambda>0$, this can be verified only if $E_{c^{y} / r}>E_{c^{o} / r}$, that is if $\sigma<1$.

As an evident consequence, we can emphasize the cases where under-accumulation and double dividend are incompatible : when the balanced environmental reform requires an decrease of the labor tax rate $(\Lambda<0)$, that is if both taxes are Laffer-efficient, or when it requires an increase of the labor tax rate if $\sigma \geqslant 1$, because in this last case, the elasticity of the young consumption to the interest rate is nil or negative (for example, if the utility 
function is Cobb-Douglas or logarithmic).

Proposition 4 If $\hat{k}<\hat{k}_{\theta}$ or $\hat{k}>\hat{k}_{g}$, the environmental fiscal policy gives rise to a conflict between the environmental dividend and the optimality issue.

Proof. The reduction of pollution needs, in any case, a decrease of aggregate consumption which is not desirable from the optimality point of view, when $\hat{k}<\hat{k}_{\theta}$ or $\hat{k}>\hat{k}_{g}$. Indeed, if $\hat{k}>\hat{k}_{g}$ (resp. $\hat{k}<\hat{k}_{\theta}$ ), there is over-accumulation (resp. under-accumulation) and any decrease of aggregate consumption needs an increase (resp. a decrease) of per capita capital stock which moves farther away from the social optimum.

There are here, in fact, two different cases. In the case of under-accumulation under the modified golden rule, the reduction of the pollution can not be socially justified and the pursuit of the first dividend leads to a decrease of pollution and of per capita capital stock under their optimal levels $\left(\pi\left(\hat{k}_{\theta}\right)\right.$ and $\left.\hat{k}_{\theta}\right)$. But in the case of over-accumulation, the competitive level of pollution may be either too great or too low compared with its optimal level (see Figure 1). When it is already too low, the same results apply. But when the initial pollution stock is too great, the environmental fiscal reform will move it closer to its optimal level while getting the capital stock farther from the social optimum. In this last case, the environmental fiscal reform would be legitimate from the ecological point of view, but not from the economic one.

Let us summarize the results obtained in our propositions. A long term double dividend can only be obtained for an economy characterized by a capital stock less than the golden rule capital stock level $\left(\hat{k}_{g}\right)$ and greater then the modified golden rule one $\left(\hat{k}_{\theta}\right)$ (Proposition 3); any other initial equilibrium gives rise to a conflict between the environment and economic welfare because the improvement of economic welfare would compulsorily increase total per capita consumption (Proposition 4) and then pollution (see Figure 1). The consequence of this result is rather intuitive: the lower the social discount factor $(\theta)$, the easier it is for the necessary condition to be verified. Indeed, when the present generations are very impatient, $\theta$ is low and $\hat{k}_{\theta}$ is low, and the initial equilibrium per capita 
capital stock is more likely to be in between the modified golden rule and the golden rule. In this case, as the initial equilibrium is above the modified golden rule, the per capita capital stock has to decrease, which can occur only in the case of a decrease in savings. The usual way to obtain this result in an overlapping generations model is to introduce a lump-sum tax bearing on the workers. In our case of exogenous labor supply, the labor tax can be considered as a lump-sum tax. $\tau^{w}$ must increase (Proposition 3). Our Proposition 1 showed that such a Laffer-inefficiency case can occur.

\section{Has a generation to be sacrificed?}

In this section, we measure the welfare variation of the young and old generations in order to address the issue of the inter-generations distributional effects of the fiscal reform.

We are searching here to know if there is any possibility for the environmental reform not to imply any welfare loss for the generations bearing it. In our static framework, we consider a small departure from the initial steady-state. Let us define the compensatory income variation of the young generation $d R^{y}$ and of the old generation $d R^{o}$ as:

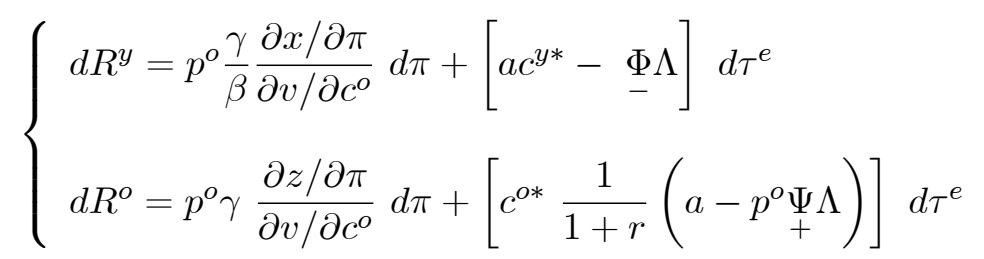

This short-term analysis of welfare concerns the very period of the fiscal reform: we examine the distributional effects between younger and older generations coexisting at a given date, and not during their life-cycle. These distributional effects depend only on the non-environmental consequences of the reform because the environmental ones are the same for both generations. We assume in this section that the first dividend is ensured $(d \pi<0)$.

Let us examine the different cases in accordance with the sign of the variation of the labor tax rate.

In the case of an increase of the labor tax rate, the young generation suffers unambigu- 
ously a non environmental welfare loss: firstly, the increase of the pollution tax increases the consumption price, and secondly the labor tax rate increase causes revenue losses. As far as the old generation is concerned, it can benefit from an increase of its nonenvironmental welfare if the discounted second-period price of consumption decreases, i.e. if $a<p^{o} \Psi \Lambda$ (cf. section 4.2). In this peculiar case, this generation enjoys a "private" double dividend because we assume that it benefits from the improvement of the environmental conditions (the first dividend is obtained). More generally, if the first dividend is greater than the non-environmental welfare loss, both generations may enjoy a global welfare gain.

When the labor tax rate decreases, both generations can either benefit or suffer from the reform. As far as the young generation is concerned, the negative price effect induced by the rise in the pollution tax rate may be compensated for by a positive revenue effect allowed by the drop of the labor tax rate. The final welfare effect is positive if its initial

consumption is not too large $\left(c^{y *}<\frac{\Phi \Lambda}{a}\right)$. The old generation suffers unambiguously an economic welfare loss because it does not benefit from the wage positive effect but it experiences the decline of the interest on its savings and the increased price of consumption.

\section{Conclusion}

In this paper, we have shown that a balanced environmental fiscal reform may result either in an increase or a decrease of the labor tax rate, depending on the elasticities of consumption and on the initial tax rates. In both cases, the existence conditions of a double dividend rely on the initial per capita capital stock and on the intertemporal elasticity of substitution. Our first conclusion is that, whatever the initial capital intensity of the economy, the double dividend cannot be obtained if the intertemporal elasticity of substitution is equal or greater than unity. Furthermore, if this elasticity is less than unity, the existence of the long term double dividend depends on the position of the economy relative to the golden rule and to the modified golden rule.

In the case of over-accumulation, the double dividend can not occur. Indeed the 
consumption of the young generation should increase while that of the old one should decrease and both taxes should be Laffer-efficient. In this last case, the environmental fiscal reform may be justified from an ecological point of view, when the initial pollution level is greater than the optimal one, but not from an economic point of view as the pursuit of a double dividend moves the economy farther from the social optimum.

In the case of under-accumulation, the existence of a long term double dividend needs a reduction of the consumption of the old generation and an increase of that of the young one and it can occur only if one of the taxes is Laffer-inefficient and if the initial capital stock is greater than the one defined by the modified golden rule.

The analysis of the distributional effects between younger and older generations coexisting at a given date shows that the environmental fiscal reform always induces a non-environmental welfare loss for one of the existing generations: the young one when

the reform bears ex post on wages, the old one when it bears on capital. For nobody to be harmed, the first dividend needs to be sufficiently high.

\section{References}

[1] W.J. Baumol and W.E. Oates, "The Theory of Environmental Policy", Cambridge University Press, 2nd edition, (1988).

[2] F. Bosello, C. Carraro and M. Galeotti, The Double Dividend Issue: Modelling Strategies and Empirical Findings, Environment and Development Economics, 6 (1), 9-45 (2001), doi:10.1017/S1355770X01000018.

[3] A.L. Bovenberg and L.H. Goulder, Optimal Environmental Taxation in the Presence of Other Taxes: General Equilibrium Analysis, American Economic Review, 86 (4), 985-1000 (1996).

[4] A.L. Bovenberg and B.J. Heidjra, Environmental Tax Policy and Intergenerational Distribution, Journal of Public Economics, 67, 1-24 (1998), doi:10.1016/S00472727(97)00064-9. 
[5] A.L. Bovenberg and R.A. de Mooij, Environmental Levies and Distortionary Taxation, American Economic Review, 84 (4), 1085-1089 (1994).

[6] A.L. Bovenberg and R.A. de Mooij, Environmental Taxes and Labor-Market Distortions, European Journal of Political Economy, 10, 655-683 (1994), doi:10.1016/01762680(94)90032-9.

[7] A.L. Bovenberg and R.A. de Mooij, Environmental Tax Reform and Endogenous Growth, Journal of Public Economics, 63, 207-237 (1997), doi:10.1016/S00472727(96)01596-4.

[8] A.L. Bovenberg and F. van der Ploeg, Environmental Policy, Public Finance and the Labour Market in a Second-Best World, Journal of Public Economics, 55 (3), 349-390 (1994), doi:10.1016/0047-2727(93)01398-T.

[9] A.L. Bovenberg and F. van der Ploeg, Environmental Policy, Public Goods and the Marginal Cost of Public Funds, The Economic Journal, 104, 444-454 (1994).

[10] A.L. Bovenberg and F. van der Ploeg, Tax Reform, Structural Unemployment and the Environment, Nota di Lavoro, 95.6, FEEM, Milan (1995).

[11] A.L. Bovenberg and F. van der Ploeg, Optimal Taxation, Public Goods and Environmental Policy with Involuntary Unemployment, Journal of Public Economics, 62, 59-83 (1996), doi:10.1016/0047-2727(96)01574-5.

[12] M. Chiroleu-Assouline and M. Fodha, Double Dividend with Involuntary Unemployment: Efficiency and Intergenerational Equity, Environmental and Resource Economics, 31 (4), 389-403 (2005), doi: 10.1007/s10640-005-2040-7.

[13] D. de la Croix and Ph. Michel, "A Theory of Economic Growth: Dynamics and Policy in Overlapping Generations", Cambridge University Press (2002).

[14] P.A. Diamond, National Debt in a Neoclassical Model, American Economic Review, 55, 1126-1250 (1965). 
[15] O.N.E. Fisher and C. van Marrewijk, Pollution and Economic Growth, Journal of International Trade and Economic Development, 67 (1), 55-69 (1998).

[16] L.H. Goulder, Environmental Taxation and the "Double Dividend": A Reader's Guide, International Tax and Public Finance, 2, 157-183 (1995), doi: 10.1007/BF00877495.

[17] L.H. Goulder, Effects of Carbon Taxes in an Economy with Prior Tax Distortions: An Intertemporal General Equilibrium Analysis, Journal of Environmental Economics and Management, 29, 271-297 (1995), doi:10.1006/jeem.1995.1047.

[18] L.H. Goulder and R.N. Stavins, An eye on the future, Nature, 419, october, pp. 673-674 (2002).

[19] R.B. Howarth and R.B. Norgaard, Intergenerational Choices Under Global Environmental Change, in "The Handbook of environmental economics" (D.W. Bromley, Ed.), Blackwell Handbooks in Economics, 111-138 (1995).

[20] T. Ihori, "Public Finance in an Overlapping Economy", Mc Millan Press LTD (1996).

[21] A. John, R. Pecchenino, D. Schimmelpfennig and S. Schreft, Short-Lived Agents and the Long-Lived Environment, Journal of Public Economics, 58, 127-141 (1995), doi:10.1016/0047-2727(94)01459-2.

[22] A. John and R. Pecchenino, An Overlapping Generations Model of Growth and the Environment, The Economic Journal, 104, 1393-1410 (1994).

[23] H. Konishi and F. Perera-Tallo, Existence of steady-state equilibrium in an overlapping-generations model with production, Economic Theory, 9, 529-537 (1997), doi: $10.1007 / \mathrm{s} 001990050140$.

[24] L.J. Kotlikoff and L.H. Summers, Tax Incidence, in "Handbook of Public Economics" (A.J. Auerbach and M. Feldstein, Eds.), 2 (16), Elsevier Science Publishers B.V., North-Holland, (1987). 
[25] G. Marini and P. Scaramozzinno, Overlapping Generations and Environmental Control, Journal of Environmental Economics and Management, 29, 64-77 (1995), doi:10.1006/jeem.1995.1031.

[26] W.E. Oates, Pollution Charges As a Source of Public Revenues, Resources of the Future Discussion Paper, QE92-05, (1991).

[27] I.W.H. Parry, Pollution Taxes and Revenue Recycling, Journal of Environmental Economics and Management, 29 (3), 64-77 (1995), doi:10.1006/jeem.1995.1061.

[28] D.W. Pearce, The Role of Carbon Taxes in Adjusting To Global Warming, The Economic Journal, 101, 938-948 (1991).

[29] J.M. Poterba, Global Warming Policy: A Public Finance Perspective, Journal of Economic Perspectives, 7 (4), 47-63 (1993).

[30] S. Proost and D. van Regemorter, The Double Dividend and the Role of Inequality Aversion and Macroeconomic Regimes, International Tax and Public Finance, 2, 207219 (1995), doi: 10.1007/BF00877497.

[31] D. Terkla, The Efficiency Value of Effluent Tax Revenues, Journal of Environmental Economics and Management, 11, 107-123 (1984), doi:10.1016/0095-0696(84)90010-X. 